\title{
27 DEFINING AWAY THE DIGITAL DIVIDE: A CONTENT ANALYSIS OF INSTITUTIONAL INFLUENCES ON POPULAR REPRESENTATIONS OF TECHNOLOGY
}

\author{
Lynette Kvasny \\ Duane Truex \\ Department of Computer Information Systems \\ Georgia State University \\ University Plaza \\ Atlanta, Georgia 30303
}

U.S.A.

\begin{abstract}
It is our contention that information technology is a cultural commodity whose influence is spread through economic and political action of institutions such as the government and corporations. Informed by Bourdieu's sociology of language, we conduct a content analysis of political speeches regarding "digital opportunities" delivered by U. S. government officials. In this analysis we demonstrate how institutions actively (re)produce and legitimize popular representations of technology and its role in the new economy. The broader implication of this analysis is to offer a way in which information systems research can consider the larger socio-political context in which so many of our research activities and debates are situated.
\end{abstract}

\section{INTRODUCTION}

Until recently the "digital divide" was understood to be a reference to classes of people at risk of being excluded from the rising tide of economic prosperity fueled by great advances in information technology. It was a dialog 
about disempowerment, poverty, and disenfranchisement in the midst of a larger discourse in which access to information technologies was given to be a necessary condition of participation in the new economy (U.S. Department of Commerce 2000). In the midst of this discourse, governments, researchers, and politicians have turned attention to how to address the digital divide and resolve some of the intractable problems arising within. We sound an alarming note on how those lacking access to digital communication technologies are suddenly being cast as members of the newly empowered group referred to as the "new market," and how, by a linguistic slight of hand, entire populations may be defined away without any serious discussion of the issues of reduced economic, cultural, and social capital.

This paper critically analyzes U.S. government speeches concerning digital opportunity and digital inclusion. Building upon on a previous paper (Kvasny and Truex 2000) in which Bourdieu's theoretical framework was offered to inform future information systems research agendas, we present empirical data that has been examined through this theoretical lens using content analysis. The analysis attempts to understand how U.S. government policies aimed at transforming the digital divide into digital opportunities and how industry efforts to gain digital dividends may instead be construed as forms of symbolic violence (Bourdieu 1998). The digital divide is presented as a pedagogical case for understanding how and why information systems researchers can consider this broader socio-political context in which our research activities and debates are situated.

\section{MOTIVATION}

In common parlance, the "new economy" is defined as the transformation of the economy from one based on agriculture and manufacturing into one based on services and high-technology skills (Greenspan 2000). Information technology enables firms and governments to push the limits of economic efficiency. "Developed" countries are faced with a shortage of skilled labor and are, therefore, trying to attract qualified labor from "developing" countries. This has a dual effect for the developing nations: the flow of remittances into the country increases, but they lose qualified workers for their own national development (United Nations 2000). Human talent becomes just another one of the commodified natural resources exported for consumption in the developed world. For workers worldwide, this practice leads to a decline in job security and solidarity because individuals must now compete in a global labor force. Long-term employment in one company becomes increasingly rare. It signals a cultural change where loyalty to institutions and places becomes a liability. Those who do manage to obtain longevity are seen as either having a lack of 
initiative or as simply being incompetent. This further signals an "every-manfor-himself" employment marketplace in which those most mobile and the most in demand command premium payments at the expense of all others. It values short-term planning horizons and short-term relations. It also leads to a loss of cumulative and organizational knowledge capital, and a loss of solidarity among those in the organizational workplace.

This loss of solidarity and collective reference is also seen in the management ranks where the focus is on short-term financials. This leads to a reign of flexibility with recruitment on temporary contracts, repeated downsizing, and competition within firms by profit centers. Managers are individually monitored and controlled with practices such as pay-for-performance, individual objective setting, bonuses, and incentive based on individual merit. Managers act more like independent proprietors, often abdicating their social responsibility to their subordinates. Therefore, it is not surprising that talk of trust, knowledge sharing, communities of practice, and corporate culture are prevalent because the organization is stripping its workers' commitment through short-term employment. In a world of downsizing, anxiety, and demoralization, there is a strong need on the part of management to give a discourse of continuity to workers (Bourdieu 1998).

Information technologies have allowed for enormous flexibility in several key dimensions. Economic capital flows from place to place electronically. Intellectual capital is captured and distributed in much the same fashion. Virtual teams are assembled when and where specific skill sets are required. When the task is accomplished, the team is dismantled. Temporary or full-time workers move on to new tasks, new settings, new teams. Management becomes increasingly virtual in a world of increasingly virtual organizational and social arrangements. In this new economy, the traditional employment covenant has been discarded (Truex et al. 1995). Skill sets change rapidly and the employee must take responsibility for gaining these skills and keeping them current. Retraining is akin to school exams within the enterprise where employees have to prove their mastery of new skills and competencies. Insecurity and a sense of unworthiness are being reinforced because the aptitudes that served workers well in the past are now being devalued and replaced with often short-lived knowledge-based skills. Such messages coupled with the structural violence of knowing that the people next door as well as people on the other side of the globe can take one's job are perquisites for creating a submissive and exploitable workforce (Bourdieu 1998).

In short, the new economy is fueled and driven by information and communications technologies. Thus it has become a matter of faith that everyone must be technology literate, web connected, and willing to change at Internet speeds. How are we to make sense of all this? 


\section{THE GOVERNMENT AS A CULTURAL FORCE}

Viewing the government as a cultural force can help us make sense of this new economy. This powerful institutional force has an important role in warranting the legitimacy of the social changes arising from the new economy. The government has a pedagogical role in presenting these changes as certain, unstoppable, and part of the natural order of things. It is, of course, also in the interest of this powerful institution to shape the discourse so that it may manage the trajectory and expansion of the economy and in so doing legitimize its own position. Thus one should ask what is and what should be the role of government with respect to technology development and diffusion? Is it to "cheer lead" the new economy or to help construct it in ways that benefit society?

This analysis suggests that we should seriously examine an unquestioned buy-in to the new economy as a further evidence of a very limited view of progress. We contend that the role of government institutions in shaping this evolutionary reality would be more than merely garnering support for an uncritical view that all arising from this new economy is universally good. There is too much at stake to be left to chance. So the question becomes, what is the role of government in relation to the new economy?

\subsection{The Role of Government in the New Economy}

The federal government has the charge of ensuring the vitality of U.S. industrial and political efforts at home and abroad. The economic policies and strategies rapidly shifted from an old to a new economy focus in the mid-1990s. A review of the Economic Report of the President (U.S. Government Printing Office 1997) indicates that the government targeted the Internet and electronic commerce as the primary means for sustaining U.S. supremacy in world markets. These sentiments were echoed in the five policy principles set forth by former President Clinton and Vice President Gore's Framework for Global Electronic Commerce (White House 1997):

1. The private sector should lead.

2. Governments should avoid undue restrictions on electronic commerce.

3. Where governmental involvement is needed, its aim should be to support and enforce a predictable, minimalist, consistent, and simple legal environment.

4. Governments should recognize the unique qualities of the Internet.

5. Electronic commerce over the Internet should be facilitated on a global basis. 
To situate these policy principles in the current analysis, one must take into account the U.S. economic environment during the time in which these statements were made. At this time, domestic prosperity was at a low, worker productivity was down, and the budget deficit was growing. Education quality was relatively low in comparison to other developed countries, income inequity was high, and poverty was rampant. In addition, aging baby boomers were placing additional fiscal strain on the future economic viability. The situation abroad also looked vexing. The Cold War was at its end and there was growing support for emerging economies in Latin America and Asia. Therefore, globalization, the spread of democracy, and the opening of world markets became dominant themes. To combat these domestic and international threats to U.S. prosperity, political leaders adopted a strategy of finding a specialization in the world market that could be exploited to secure the country's advantage and economic success. Computing technologies and services became that core competency (Selfe 1999).

It was determined that technology and economic growth would be joined both domestically and globally. The first step in this process was the development of an infrastructure capable of supporting this goal. Former Vice President Gore shared the vision of a Global Information Infrastructure (Office of the Vice President 1994) and the National Information Infrastructure (Office of the Press Secretary 1993). Once the infrastructure was in place, educational institutions where enlisted to provided the information technology literacy and training that would enable the average citizen to surf the information superhighway. To continually apply pressure and energy on the system, business projected a value system favoring progress that would convince citizens of the benefits of using Internet and communication technologies. This was accomplished by stimulating the appetite for technology that increased hardware and software development, and by stimulating the appetite for prosperity among present and future workers (Selfe 1999).

Thus the government established a unified force for maintaining and legitimizing an agenda for technology literacy and universal access which, in turn, sustains a private sector bent on creating and extending the world market for U.S. technologies. Elston (2001) goes even further in stating that the balance of global economic power has shifted from governments to corporate boardrooms. She cites a study by the Institute for Policy Studies that compared corporate sales and gross domestic products, and concluded that 51 of the largest 100 economies in the world are corporations, not countries. This means that General Motors is now bigger than Denmark, IBM is bigger than Singapore, and Sony is bigger than Pakistan. The leaders of these large economies clearly have the clout to commandeer a discourse about technology and the new economy. But how is this agenda gently imposed on those who do not or who cannot 
follow suit? For this we need to understand the relation of culture and of language to the use and acceptance of technology. We believe that the work of the French Sociologist Pierre Bourdieu offers some profound insights to help answer this question.

\section{THEORETICAL FRAMEWORK}

Culture is unthinkable without language, according to Bourdieu. He insists that the study of language cannot be analyzed and understood in isolation from its cultural context and the social conditions of its production (Jenkins 1992). His analysis of language is concerned with the manner in which domination is achieved through the manipulation of symbolic and cultural resources, and with the collusion of the dominated (Jenkins 1992). This theoretical perspective offers a lens through which to examine how linguistic practices and products are informed by and molded by the pervasive power differentials reflected in societies.

Language is a form of practice that can be understood as the product of the relation between a "linguistic habitus" and a "linguistic market" (Bourdieu 1991). ${ }^{1}$ The linguistic habitus is the set of pre-dispositions gained as one learns how to speak in varied social contexts such as schools, places of employment, public settings, family gatherings, and universities. It provides one with the ability to gauge the reception that the given speech will yield. The linguistic habitus also takes on a physical or bodily dimension called the hexus that presents itself in a person's specific accent and speaking style. These are decidedly cultural and identifiable. Just like the characters in G. Bernard Shaw's Pygmalion, we identify the London Cockney, the New York Bronx accent, or the rural Southern accent with various attributes, attitudes, and stereotypes. Hence, speech, grammar and vocabulary are indices of social position.

The linguistic habitus informs and constrains one with speaking competencies that are brought to bear within the various linguistic markets. A linguistic market takes the form of sanctions and censorship, and defines what cannot be said as much as what can (Jenkins 1992). In the linguistic market, the speech act is received and assigned an actual value by the listener. The value of the utterance, however, is not based solely on linguistic terms. What happens between parties in a linguistic exchange also derives from the whole social structure that is present in the interaction. Gender, socio-economic status, race, age, and a variety of other status indicators come into play. In other words,

'The reader is directed to Table 1 for a summary of Bourdieu's terminology 
language is not only communicative; there are also signs of wealth intended to be evaluated and appreciated and signs of authority intended to be believed and obeyed (Bourdieu 1991).

All linguistic exchanges, therefore, are situated encounters between actors endowed with differing degrees of socially structured resources and competencies. Furthermore, all linguistic exchanges bear traces of the social structure that it expresses and helps to reproduce. To illustrate these concepts, Bourdieu discusses "strategies of condescension" employed by those with large quantities of linguistic capital. By that he means those who have acquired the ability by birthright, wealth, or education are better equipped to tacitly adjust their speech to meet the dictates of the market. Since linguistic capital, the capacity to produce appropriate expressions for a particular market, is unevenly distributed, those with sufficient linguistic capital are better able to exploit the system.

Linguistic competency is a key concept for analyzing linguistic exchanges. Bourdieu sees Noam Chomsky's theory in which competency is understood as the capacity of a speaker to produce an unlimited set of grammatically correct utterances as insufficient. To Chomsky, linguistic competence is innate and genetically encoded in humans. It is a structural and physiological property of the brain. His principal interests are not in performative langue but in the structures allowing or enabling speech (Baker and Hacker 1984; Chomsky 1965, 1969, 1986; Cook and Newson 1996). However, for Bourdieu, competency also lies in the speaker's ability to produce speech that is appropriate for the situation. His interests are, unlike Chomsky's, performative and based on social competencies constrained by social and cultural structures. In this practical sense, the linguistic habitus enables speakers to create sentences that are tacitly adjusted to the relations of power between the speaker and the hearer. So it is not only a capacity to produce grammatically correct sentences; it is also the capacity to make oneself heard and obeyed. Therefore, power and authority are implicit in all communicative situations (Bourdieu 1991).

The notion of institution is tightly related to competency. Institutions are not organizations per se but any relatively durable sets of social relations that endow individuals with power, status, and resources of various kinds (Bourdieu 1991). It is the institution that endows the speaker with the authority to speak on its behalf. Moreover, the listener must recognize this power as such. The use of microphones, photographers, and transcribers add credibility to the speaking engagement, as do symbolic devices such as respectful acknowledgements and references to audience members. Hence power is not based on words alone; power is conferred to the spokesman by the authority of a social institution.

One may have well-founded doubts about the applicability of this theory to purely communicative situations such as casual conversations between friends. However, this theory is appropriate for the current study that examines political 
speeches. Political speech is the site par excellence in which agents seek to form and transform their vision of the world and thereby the world itself. Words become actions and the symbolic character of power is at stake (Bourdieu 1991). Slogans, commentaries, commitments, and promises used by politicians form a "labor of representation" by which they attempt to construct and impose a particular view of the world while at the same time they attempt to mobilize support of those upon whom their power ultimately depends (Bourdieu 1991). It is very akin to the concepts of translation and enrollment in Latour's Actor Network Theory (1987).

This labor of representation also serves a second function of accumulation and sustenance of political capital. In order for politicians to excel, they must appeal to others outside of the political field. They face a constant battle of gathering support or "political capital," which can take both material (campaign contributions) and symbolic (votes) forms.

To be effective, political speech requires the active compliance and belief on the part of the listener. This is an example of a general phenomenon known as symbolic power or symbolic violence. Symbolic power is invisible in that physical force is not exerted. Individuals comply with the wishes of the powerful because they share a belief in the legitimacy of the need to adapt to the dominant culture. Symbolic power requires, as a condition of its success, that those subjected to it believe in the legitimacy of power and the legitimacy of those who wield it (Bourdieu 1991). This tends to reproduce and sustain power differentials because the arbitrary nature of the hierarchy is not challenged. Words are taken unconsciously in good faith as inevitable. Thus power is exercised and at the same time disguised.

Symbolic violence has three interrelated functions: cognition, communication, and social differentiation (Swartz 1997). The cognitive function of symbolic violence provides a means for categorizing, ordering, and classifying the social world. These classificatory schemes are encoded with deep structural meanings. Therefore, the internal logic of how the social world is structured and defined must be shared so that there is unification in thought and understanding. This is the communication role of symbolic violence. Finally and what Bourdieu stresses is the political function of symbolic violence. Symbol systems provide mechanisms for creating and legitimizing social differentiation schemes for ranking groups by encouraging the dominated to accept these hierarchies as self-evident. Applying these functions of symbolic violence to political speeches, we are able to pinpoint the ways in which language is used to gently impose the dominant vision of a technology driven future onto communities that have historically been excluded from participation in the new economy. 


\section{RESEARCH METHODOLOGY}

Bourdieu's sociology of language was used to inform a content analysis of transcripts of speeches made by U.S. government officials concerning the digital divide. These speeches were gathered from the White House web site that featured documents related to the "New Markets Tour." The tour consisted of visits by the former President and other high-ranking government officials as well as an entourage of corporate CEOs to historically underserved communities such as East Palo Alto, Harlem, Appalachia, and the Navaho Nation. Both authors performed the analysis, and the HyperRESEARCHcontent analysis software was used to facilitate the coding of the texts. ${ }^{2}$ Our approach has significant similarities with traditional content analysis but with refinement derived from the literature and from the previous published work of one of the authors.

In overview, the analysis was conducted in three stages from both a topdown and inside-out fashion. The process began with a complete meta-level review of the transcripts. Through iterative readings of these texts, initial candidate themes were identified as they were introduced in the texts. These themes were grouped and then cross-mapped to a higher-level concept set drawn from Bourdieu's theory. Table 1 provides a brief description of the constructs.

Table 1. Core Theoretical Concepts (from Kvasny and Truex 2000)

\begin{tabular}{|l|l|}
\hline \multicolumn{1}{|c|}{ Key Term } & \multicolumn{1}{c|}{ Application to Information Technology } \\
\hline Field & $\begin{array}{l}\text { Information technology organization or a given technology system } \\
\text { under investigation }\end{array}$ \\
\hline Habitus & $\begin{array}{l}\text { Expectations, aspirations, and attitudes toward technology; informs } \\
\text { practices, e.g., how and if one engages technology. }\end{array}$ \\
\hline Symbolic Violence & $\begin{array}{l}\text { Use of technology to enforce decisions; decision to limit or deny } \\
\text { access to technology or use of technology; technology used for } \\
\text { surveillance or control }\end{array}$ \\
\hline Cultural Capital & $\begin{array}{l}\text { Exposure to, previous experience with, and familiarity with } \\
\text { information technologies; information technology credentials }\end{array}$ \\
\hline Symbolic Capital & $\begin{array}{l}\text { Use of highly technical language, sharing of technical expertise, } \\
\text { removing manual processes in favor of technological processes, } \\
\text { denying training in new technology }\end{array}$ \\
\hline Social Capital & Access to relationships with others knowledgeable about technology \\
\hline Economic Capital & $\begin{array}{l}\text { Ability to acquire technology and training; choices to allocate } \\
\text { resources to the procurement of technology }\end{array}$ \\
\hline
\end{tabular}

${ }^{2}$ For more information and demonstration copies of HyperRESEARCH, go to http://www.researchware.com. 
Table 2. Candidate Content Variables Mapped to Bourdieu's Linguistic Framework

\begin{tabular}{|l|l|}
\hline \multicolumn{1}{|c|}{ Initial Mapping } & \multicolumn{1}{c|}{ Final Mapping } \\
\hline Commitment to policies & Political capital \\
\hline Definitions of digital divide & Cognitive function of symbolic violence \\
\hline $\begin{array}{l}\text { Link between technology skills and } \\
\text { employment opportunities }\end{array}$ & Cognitive function of symbolic violence \\
\hline Under-served communities as new markets & Cognitive function of symbolic violence \\
\hline Sharing in economic growth and prosperity & $\begin{array}{l}\text { Knowledge integration function of symbolic } \\
\text { violence }\end{array}$ \\
\hline $\begin{array}{l}\text { Moral obligation to include under- } \\
\text { represented communities }\end{array}$ & $\begin{array}{l}\text { Knowledge integration function of symbolic } \\
\text { violence }\end{array}$ \\
\hline Technology as the great equalizer & $\begin{array}{l}\text { Knowledge integration function of symbolic } \\
\text { violence }\end{array}$ \\
\hline
\end{tabular}

Table 3. Content Codes with Sample Text

\begin{tabular}{|l|l|l|}
\hline Final Mapping & \multicolumn{1}{|c|}{ Definition } & \multicolumn{1}{c|}{ Sample Text from Data Source } \\
\hline Political capital & $\begin{array}{l}\text { Making commit- } \\
\text { ments to gain the } \\
\text { support of others }\end{array}$ & $\begin{array}{l}\text { Clinton Remarks on Bridging Digital Divide } \\
\text { TEXT 4166,4408 } \\
\text { "I am signing an executive memorandum to } \\
\text { ensure that closing the digital divide will be a } \\
\text { vital goal...throughout the federal government." }\end{array}$ \\
\hline $\begin{array}{l}\text { Cognitive function } \\
\text { of symbolic } \\
\text { violence }\end{array}$ & $\begin{array}{l}\text { Imposing a consen- } \\
\text { sus or common sense }\end{array}$ & $\begin{array}{l}\text { Daley Digital Divide Summit } \\
\text { TEXT 1133,1187 } \\
\text { "You know how important the Internet is to our } \\
\text { economy." }\end{array}$ \\
\hline $\begin{array}{l}\text { Knowledge } \\
\text { integration } \\
\text { function of } \\
\text { symbolic violence }\end{array}$ & $\begin{array}{l}\text { Channeling deep } \\
\text { structural meanings } \\
\text { so members of the }\end{array}$ & $\begin{array}{l}\text { Rhode FCBA Speech } \\
\text { TEXT 14182,14334 } \\
\text { "We are also working to make certain that our } \\
\text { philosophies of innovation, competition, open } \\
\text { markets and universal service are adopted } \\
\text { around the world." }\end{array}$ \\
\hline $\begin{array}{l}\text { Political function } \\
\text { of symbolic } \\
\text { violence }\end{array}$ & $\begin{array}{l}\text { Encouraging the } \\
\text { acceptance of } \\
\text { hierarchies of social } \\
\text { distinctions }\end{array}$ & $\begin{array}{l}\text { Rhode Diversity Speech } \\
\text { TEXT 4128,4298 } \\
\text { "The same technology exists in Europe, Asia, } \\
\text { and Latin America. But there is an explosion of } \\
\text { growth in the U.S. that has other nations striving } \\
\text { to replicate our success." }\end{array}$ \\
\hline $\begin{array}{l}\text { Strategies of } \\
\text { condescension }\end{array}$ & $\begin{array}{l}\text { Negating power and } \\
\text { competence while at } \\
\text { the same time } \\
\text { gaining symbolically } \\
\text { from this act }\end{array}$ & $\begin{array}{l}\text { Daley Graduation Speech } \\
\text { TEXT 755,937 } \\
\text { "In fact, if the Mayor knew how bad I was on a } \\
\text { computer...I am not sure he would have invited } \\
\text { me to speak." }\end{array}$ \\
\hline
\end{tabular}


After the meta-analysis, the researchers conducted a more traditional content analysis of the texts to further refine the methodological issues and to surface additional content variables. Table 2 provides the initial set of content variables arising from the language of the political speeches and the mapping to the set of variables consistent with Bourdieu's language constructs. Length prohibits a fuller explication of this mapping but the reader is encouraged to see Bourdieu (1991) for further developments.

Finally, Table 3 three maps actual textual samples from reports generated from the larger coded set of texts. These examples are intended to be illustrative of the background coding.

It should be noted that the approach used in this study was not a grounded theory approach. That is, the researchers entered into the examination of the texts with an initial set of predetermined content variables extracted from Bourdieu's conceptual framework. We did not expect the categories to emerge wholly from iterative readings of the text. Based on the previous experiences of one of the authors with content analysis (Klein and Truex 1996), it was expected that the pool content variables would be amended during the analysis, but that the initial set would provide a reasonable starting point that would tie back to Bourdieu's theory.

\section{INTERPRETATION OF RESULTS}

Symbolic violence is the dominant theme that emerges from this analysis. These speeches, by symbolic force, impose a view of technology progress as pure reason onto the audience. Statements such as "In the new economy, access to the tools of the information age will determine opportunity"(Rohde Diversity Speech, TEXT 2496,2587) and "The longest economic expansion in our nation's history...is a result of information technologies" (Daley Harlem Speech, TEXT 2544,2881 ) treat technology as an unstoppable force of nature that cannot be questioned. This serves a cognitive function of defining technology in terms of bipolar opposites such as growth/stagnation, new economy/old economy, and progress/retreat.

By creating cognitive distinctions, they also create social groupings. For instance, there are those "doomed to exist at the margins because they lack digital skills," and there are those that "stand to prosper because they possess digital skills." This distinction is seen repeatedly in statements such as "Without that access, without those skills, the divide becomes greater and greater and greater"(Clinton Palo Alto, TEXT 18715, 18832).

However, these distinctions are arbitrary in that they do not accurately represent social reality. Nor are the political utterances necessarily consistent 
from political address to political address. There are contradictions and interesting interpretations of how conflicting governmental policies might interact. For example, it was posed as a fundamental law "that the high-tech industry is in a constant war for talent" (Clinton Palo Alto Speech, TEXT 17799, 18088). Moreover "the second law is that technology...information technology and the Internet can be the great equalizer" (Clinton Palo Alto Speech, TEXT $18309,18414)$. How does this compare with U.S. corporate employment practices and with industrial programs to retrain the large pool of workers who are yet to be digitally literate?

In the speeches, technology is treated as this magical force that will erase centuries of discrimination and inequality. This is clearly not the case for, as one CEO noted, "business must quit giving lip service and provide the jobs and give the access"(Clinton Palo Alto Speech, TEXT 22953, 23174). Even Bill Clinton himself openly asked why some individuals are not able to translate years of engineering, math, and science training into career positions. One possible explanation is that this notion of technology as the great equalizer fails to consider that social, economic, and cultural capitals are not equally distributed. For instance, when individuals are being interviewed for career positions, the "fit" of the candidate is highly relevant. Is this person someone we would like to work with? In other words, is this person sufficiently similar to us? Those not socialized in the American middle class milieu have greater difficulty in finding a natural "fit" in major corporations. With fewer friends or family members with corporate jobs to serve as mentors or to provide job leads, these candidates lack significant social capital. Simple cultural competencies such as formal dining etiquette and making international travel arrangements can be a daunting experience. Even idle small talk with co-workers is challenging when one does not participate in similar recreational activities, consume similar goods, listen to similar music, or watch similar television programs.

Another contradiction that emerges from these texts is the level of commitment to bridging the divide. In the text, the former President remarked "we have to raise the cap on visas to bring in people from other countries who are trained in these skills. And I'm pro-immigration. I'm all for this. We've got to do it, we've got to keep these industries going. We've got to do the right thing" (Clinton Palo Alto, TEXT 19878,20125). In another speech he says, "I want Americans to look first to people here at home, who need work and education, who need technology and opportunity"(Clinton Indian Nation, TEXT $10339,10460)$. This contradiction may possibly stem from the fact that political figures have to meet the needs of competing constituents. On the one hand, a pro-American stance is needed to appease the average citizen while a proimmigration stance is needed to appease the business community. On the other hand, the use of H1-B visas might pose a short-term solution until the 
educational institutions can produce a sufficient quantity of U.S. talent. Either way you look at this contradiction, the primary interest is to sustain economic growth.

The texts also take on a nurturing tone that helps to ensure the complicity of the audience members while at the same time hiding the ulterior motives for serving these communities. So when the former President states "we can use new technology to extend opportunity to more Americans than ever before; we can truly move more people out of poverty more rapidly than ever before" (Clinton Palo Alto, TEXT 5045,5344), it hides the interests that underlie the statement. Technology firms see these communities as new markets that they can tap to sustain growth, and the politicians view these communities as sources of additional votes.

In addition to masking interests, these calls for social inclusion ignore the fact that structural forces beyond the physical access to technology may act to perpetuate the divide. As one prominent CEO noted, "just focusing on access to computers is a fairly narrow way to look at these problems" (Gates Digital Dividends Speech, TEXT 5711,5842). Van Dijk and Hacker (2000) offer a multifaceted framework for understanding access. They conceptualize access in terms of four hurdles on the way to the information and network society (Table 4).

The core argument presented by these authors is that we cannot assume that structural divides will subside with an increase in material access. They suggest that when material access is more universal, structural divides concerning digital skills and usage will come to the fore. As new technologies offer new opportunities for citizen participation and consumer interest, new inequalities of a nature not known before may erupt. Moreover these differentials must be contested, if one chooses to do so, with means other than the traditional ones of government subsidies and policies.

Table 4. Defining Access

\begin{tabular}{|l|l|}
\hline Type of Access & \multicolumn{1}{c|}{ Definition } \\
\hline Psychological & $\begin{array}{l}\text { Lack of any digital experience caused by lack of interest, computer fear, } \\
\text { and unattractiveness of the new technology }\end{array}$ \\
\hline Material & Lack of possession of computers and network connections \\
\hline Digital Skills & $\begin{array}{l}\text { Lack of digital skills caused by insufficient user-friendliness and } \\
\text { inadequate education or social support }\end{array}$ \\
\hline Usage & Lack of significant usage opportunities \\
\hline
\end{tabular}


For instance, the U.S. government's effort to migrate services to the Internet raises immediate questions for universal access. While the nation may be prepared to tolerate different levels of access to commercial goods and services, government services carry the additional burden of providing equitable access. The prospect of a digitally privileged clientele breezing through taxes, contract opportunities, and environmental hazard databases while a paperbound proletariat waits in line is detestable to democratic culture (Birdsell and Muzzio 1999).

This question of universal access is sharpest in the areas of government services that stand to be used heavily by the very population groups least likely to enjoy easy access to the Internet: the urban and rural poor, seniors, the disabled, and the less educated. Online information about public housing, notices of changes in the operation of public assistance offices, and job databases will do little good for much of their intended public if that public is not online. In addition, most U.S. government programs simply create content without directly attempting to expand the online population (Birdsell and Muzzio 1999). Hence, government efforts to offer services "universally" over the Internet will have little impact on those that are not web-connected.

\section{CONCLUSION}

The growth of a global digital divide has become one of the critical policy issues being raised by governments, corporate and civic organizations, and the popular press. The solutions presented for bridging the divide stem in part from the creation of cognitive categories which present a more or less authorized way of seeing and constructing the world. The rhetoric about the divide has shifted to talk of digital opportunity, new markets, and digital dividends. In this paper, we have argued that an easy solution to such a persistent and perhaps insolvable problem as the digital divide is sometimes one that defines it out of existence. This should not surprise, of course. The definitional word battles surrounding the notion of the digital divide are a means of bounding the problem. If it may be defined away via political speech, it has the possibility of becoming less intractable or less visible.

What are the broader implications for information systems research? We argue that information technology is a cultural commodity whose influence is spread through economic and political action. As vendors develop new technologies and services, institutions such as governments, corporations, and schools play important roles in popularizing them and in giving meaning to them. These popular representations of technology seriously influence the use and likely impact of these systems. Hence information systems researchers must pause to 
question our underlying assumptions about technology and the powerful institutions that guide the technology agenda, or else we share in the responsibility of sustaining and reproducing an unfair system that ensures disparity under the aegis of universal access.

\section{REFERENCES}

Baker, G. P., and Hacker, P. M. S. Language, Sense and Nonsense: A Critical Investigation into Modern Theories of Language, Oxford: Basil Blackwell, 1984.

Birdsell, D. S., and Muzzio, D. "Government Programs Involving Citizen Access to Internet Services," Markel Foundation, 1999 (available online from http://www.markle.org/ news/news_pressreport_index.stm, accessed March 2001).

Bourdieu, $\bar{P}$. Language and Symbolic Power, Cambridge, MA: Harvard University Press, 1991. Bourdieu, P. Acts of Resistance: Against the Tyranny of the Market, New York: Norton, 1998. Chomsky, N. Aspects of the Theory of Syntax, Cambridge, MA: MIT Press, 1965.

Chomsky, N. Knowledge of Language: Its Nature, Origin and Use, New York: Prager, 1986.

Chomsky, N. "Linguistics and Philosophy," in Language and Philosophy, S. Hook (ed.), New York: New York University Press, 1969.

Cook, V. J., and Newson, M. Chomsky's Universal Grammar: An Introduction, Oxford: Blackwell Publishers Ltd., 1996.

Elston, S. Global Economy: Shifting the Balance of Power, Environmental News Network, January 31, 2001 (accessed February 2001; available from http://enn.com/news/ennstories/2001/01/01312001/economy_41639.asp).

Greenspan, A. "Structural Change in the New Economy," paper delivered at the National Governors' Association, 92nd Annual Meeting, State College, Pennsylvania, July 11, 2000.

Jenkins, R. Pierre Bourdieu, New York: Routledge, 1992.

Klein, H. K., and Truex, D. P. "Discourse Analysis: An Approach to the Investigation of Organizational Emergence," in Signs of Work, Semiosis and Information Processing in Organisations, B. Holmqvist, P. B. Andersen, H. Klein, and R. Posner (eds.), Berlin: Walter de Gruyter, 1996, pp. 227-268.

Kvasny, L., and Truex, D. P. "Information Technology and the Cultural Reproduction of Social Order: A Research Program," in Organizational and Social Perspectives on Information Technology, J. Stage, R. Baskerville, and J. I. DeGross (eds.), Boston: Kluwer Academic Publishers, 2000, pp. 277-294.

Latour, B. Science in Action, Cambridge, MA: Harvard University Press, 1987.

Office of the Vice President. Remarks (as Delivered) by Vice President Al Gore, A Speech at the International Telecommunication Union Plenipotentiary Conference, Kyoto, Japan. White House, September 22, 1994 (accessed October 2000; available from http://www.pub. whitehouse.gov/uri-res/I2R?urn:pdi://oma.eop.gov.us/1994/9/22/2.text.1).

Office of the Press Secretary. The National Information Infrastructure: Agenda for Action, White House, September 15, 1993 (accessed October 2000; available from http://www.pub. whitehouse.gov/uri-res/I2R?urn:pdi://oma.eop.gov.us/1993/9/16/17.text.2).

Selfe, C. Technology and Literacy in Twenty-First Century: The Importance Paying Attention, Carbondale, IL: Southern Illinois University Press, 1999.

Swartz, D. Culture and Power: The Sociology of Pierre Bourdieu, Chicago: The University of Chicago Press, 1997.

Truex, D. P., Caldow, J., and Shank, M. Reshaping the IS Culture: Understanding Organizational Culture in High-Performance Information Systems Organizations, Chicago: Society 
for Information Management and IBM Working Group on Reshaping IS Culture, Working Group Report, 1995.

United Nations. Development and International Cooperation in the 21st Century: The Role of Information Technology in the Context of a Knowledge-based Global Economy, United Nations, May 18, 2000.

United States Department of Commerce. Falling Through the Net: Toward Digital Inclusion, A Report on Americans' Access to Technology Tools. NTIA, 2000 (accessed February 2001; available from http://www.ntia.doc.gov/ntiahome/digitaldivide).

United States Government Printing Office. 1997 Economic Report of the President, United States Government Printing Office, 1997 (accessed October 2000; available from http://www.access.gpo.gov/eop).

Van Dijk, J., and Hacker, K. "The Digital Divide as a Complex and Dynamic Phenomenon.," paper delivered at the International Communication Association, Acupulco, Mexico, June 2000.

White House. Framework for Global Electronic Commerce, The White House, July 17, 1997 (accessed October 2000; available from http://www.ecommerce.gov/framewrk.htm).

\section{About the Authors}

Lynette Kvasny is a doctoral candidate at the Department of Computer Information Systems at Georgia State University. Her dissertation examines the nature of the digital divide in an economically impoverished urban community, and establishes a set of best practices for community technology centers delivering services to these populations. To date, she has published in various conference proceedings, and participated in the 2000 ICIS Doctoral Consortium. Her practical industry experience includes software development and consulting at AT\&T, Lucent Technologies, and Avaya Communications. Lynette can be reached at lkvasny@gsu.edu.

Duane Truex is an associate professor of Computer Information Systems at Georgia State University and a Leverhulme Fellow at the University of Salford, England. His first degrees were in the arts and he spent his early professional life in symphony orchestra and museum management. As a critical social theorist, his work in information systems research has generally been concerned with emancipatory issues. He also writes about information systems development and information systems research methods. He has published in Communications of the ACM, Accounting Management and Information Technologies, Information Systems Journal, IEEE Transactions on Engineering Management, the IFIP transactions series, and in various other proceedings. Duane can be reached at dtruex@gsu.edu. 